\title{
Material didático socioemocional para o ensino das cinco emoções básicas e desenvolvimento da empatia
}

Social-emotional didactic material for the teaching of the five basic emotions and development of empathy

SOUZA DE ALMEIDA, JÉSSICA; Universidade Federal do Rio Grande do Sul

almeidajssica@gmail.com

GONÇALVES CURTIS, MARIA DO CARMO; Universidade Federal do Rio Grande do Sul

00068048@ufrgs.br

\section{Resumo}

Este artigo é um desdobramento de trabalho de conclusão de curso em Design Visual, e tem como objetivo apresentar o desenvolvimento de um material didático socioemocional para crianças a partir dos 7 anos de idade. Esse material didático, baseado nas cinco emoções básicas - alegria, medo, raiva, tristeza e nojo - definidas por Paul Ekman (2003), visa promover uma experiência lúdica, divertida e interativa que incentive o aluno a entender melhor as suas próprias emoções e as emoções dos seus colegas, aumentando assim, o seu nível empático, cognitivo e emocional. 0 presente artigo apresenta a importância da empatia do contexto escolar, o conceito de empatia, a falta de empatia no contexto escolar e o design como fator de inovação no contexto escolar.

Palavras Chave: design e ensino; empatia; emoções.

\begin{abstract}
This article is an extension of a final course work in Visual Design, and has as objective present the development of a social-emotional didactic material for children from 7 years of age. This courseware, based on the five basic emotions - joy, fear, anger, sadness and disgust - defined by Paul Ekman (2003), aims to promote a fun and interactive experience that encourages students to better understand their own emotions and the emotions of their colleagues, thus increasing their empathic, cognitive and emotional level. This article presents the importance of empathy in the school context, the concept of empathy, lack of empathy in the school context and design as a factor of innovation in the school context.
\end{abstract}

Keywords: design and teaching; empathy; emotions. 


\section{Introdução}

A educação está diretamente relacionada ao sentido humano e social que conferimos a ela. Se a educação passar a ser concebida como um processo-chave de transformação social e de desenvolvimento de pessoas responsáveis, consigo e com os outros, então a educação precisa promover o aprendizado de assuntos mais profundos e importantes, como o das habilidades emocionais. (Instituto Alana, 2016).

O presente artigo é um desdobramento de trabalho de conclusão de curso em Design Visual, cuja motivação em pesquisar a educação emocional e empatia surgiu da vontade pessoal de provocar uma melhora nas relações interpessoais em crianças. Proposta motivado por uma experiência de intercâmbio social pela AIESEC1 realizado em Buenos Aires, Argentina, no qual foi possível acompanhar um programa de assistência social com crianças entre 3 e 11 anos que residem em um abrigo mantido pelo governo. Esta motivação foi reforçada pelo contato com alunos entre 8 e 11 anos de escolas de Porto Alegre, RS, durante a pesquisa de campo realizada no trabalho de conclusão de curso em Design Visual.

Partindo do pressuposto que o design é fator de inovação no contexto escolar, o objetivo deste artigo é abordar conceitos básicos relacionados ao processo de ensino-aprendizagem como as emoções, visando minimizar a carência de empatia no ambiente escolar. Como alternativa de solução do problema foi projetado um material didático socioemocional, como possibilidade de contribuição do design nesse contexto. A metodologia utilizada foi a fundamentação teórica, aliada ao conhecimento empírico adquirido pela pesquisa de campo realizada (entrevistas, observações). Foram coletadas referências atuais e nacionais.

\section{A importância da empatia no contexto escolar}

O desenvolvimento das habilidades emocionais e empáticas é fundamental no desenvolvimento da primeira infância e, embora se tenha esta consciência, pouco é feito dentro do ambiente escolar para estimular essas competências e promover as trocas, as múltiplas interações, os diálogos e as reflexões coletivas entre pessoas diferentes (Instituto Alana, 2016).

Ekman (2003), após 40 anos de estudos sobre as emoções e suas expressões faciais, classificou as emoções em cinco categorias básicas que servem de base para todas as demais: alegria, raiva, medo, tristeza e nojo. As emoções são ativadas internamente por gatilhos e são traduzidas visualmente pelas expressões faciais, de maneira igual entre todos os seres humanos. Os gatilhos podem ter como origem temas universais, ou seja, heranças do nosso patrimônio evolutivo que afetam a todos. Um exemplo disso é o medo de cobras e animais perigosos, pois não é preciso viver uma experiência traumática com um desses animais para sentir medo, essa resposta emocional já faz parte da nossa herança genética. Mas estes gatilhos também podem ser aprendidos a partir de experiências pessoais. Reconhecer as próprias emoções, e os gatilhos que as desencadeiam, é um primeiro passo para o desenvolvimento de uma inteligência emocional que irá, por sua vez, facilitar a identificação destas mesmas emoções nas outras pessoas. Saber identificar o que o outro está sentindo gera uma interação que ajuda a desenvolver a empatia, que

\footnotetext{
1 A Association Internationale des Etudiants en Sciences Economiques et Commerciales(AIESEC) foi criada em 1948 por estudantes de 6 países que queriam aproximar jovens do mundo todo. Hoje ela promove a liderança em jovens entre 18 e 30 anos por meio de intercâmbios sociais e profissionais.
} 
por sua vez, ajuda o indivíduo a entender e respeitar o outro, melhorando assim, as suas relações interpessoais (Ekman, 2003).

Quando se está familiarizado com o que desencadeia cada emoção, é possível aumentar a consciência de quando e por que as emoções ocorrem. Identificar os próprios gatilhos emocionais pode ajudar a evitar situações que despertam emoções negativas. $O$ objetivo não é ser desprovido de emoção, mas sim ter mais opções, para decidir como enfrentar as diversas situações vivenciadas. Saber identificar as emoções não implica que o sujeito irá agir de acordo, para o bem ou para o mal, porém, não saber identificar as emoções impossibilita qualquer atitude empática ou compassiva (Ekman, 2003). Concluindo, a auto-percepção das próprias emoções ajuda a melhor identificar as emoções dos outros, desta forma, a consciência emocional facilita a empatia.

Para poder desenvolver a consciência emocional e as capacidades empáticas é preciso transformar o ambiente escolar, pois a escola é o primeiro lugar que transcende o universo familiar, é o primeiro lugar onde se é confrontado com as diferenças e desigualdades. A escola é o melhor lugar para gerar discussões, trocas, interações, reflexões sobre os mais variados temas. Porém, a concepção atual de escola e educação não prioriza o desenvolvimento das capacidades socioemocionais, uma vez que o foco principal incide nas capacidades cognitivas da criança (a leitura, a escrita, a matemática). Estas capacidades cognitivas são fundamentais para o desenvolvimento da criança, entretanto, as socioemocionais também são fundamentais e precisam receber atenção (Instituto Alana, 2016).

\section{Conceito de empatia}

De acordo com o historiador, pesquisador e sociólogo Roman Krznaric (2015), 'empatia é a arte de se colocar no lugar do outro por meio da imaginação, compreendendo seus sentimentos e perspectivas e usando essa compreensão para guiar as próprias ações'. A capacidade de empatizar está presente em $98 \%$ da população, os outros $2 \%$ se refere às pessoas que não conseguem estabelecer conexão emocional, como os psicopatas e pessoas com distúrbios do espectro do autismo.

Para Ekman (2003) existem três tipos de empatia: (i) a empatia cognitiva, quando se reconhece o que o outro sente; (ii) a empatia emocional, quando se sente o que o outro sente (às vezes de forma física); (iii) e a empatia compassiva, quando surge a vontade de ajudar o outro a lidar com a situação e suas emoções. Existem algumas maneiras de ativar as emoções e a empatia, como, saber reconhecer gatilhos emocionais que despertam determinada emoção através da autoavaliação reflexiva, acessar memórias passadas de uma experiência emocional, fazer uso da imaginação, falar sobre um evento emocional passado, sentir o que o outro sente (empatia emocional), assumir voluntariamente a aparência de uma emoção - experimentos comprovaram que assumir a expressão facial de uma determinada emoção desperta os sentimentos atrelados a esta (Ekman, 2003).

Os estudos de Krznaric (2015), detectaram algumas formas de desenvolver a empatia. 0 primeiro passo é reconhecer que a capacidade de empatizar faz parte da natureza humana e que esta pode ser desenvolvida. O segundo passo é transpor as barreiras que impedem o desenvolvimento da empatia, como o preconceito, a distância física e emocional com pessoas de lugares e culturas diferentes, a tendência humana de obedecer à autoridade e se defender alegando que estava "apenas cumprindo ordens" e a exaustão psicológica produzida pela grande 
quantidade de informações negativas de todos os lugares do mundo. O terceiro passo é o aprendizado experiencial, que embora seja a abordagem mais exigente à empatia, tem o potencial de produzir as maiores recompensas. A experiência de sentir na pele como é ser outra pessoa demanda um profundo exercício de imersão e de exploração, pois é necessário ser sensível, versátil e imaginativo. Por fim, outra forma de estimular a empatia é fazer uso da arte como meio pelo qual a imaginação empática é desenvolvida. Os recursos incluem teatro, cinema, fotografia e literatura.

\section{A falta de empatia no contexto escolar}

Algumas pesquisas internacionais demonstraram uma diminuição no nível de empatia nas últimas décadas. Um estudo feito na Universidade do Michigan entre 1980 e 2010, mostrou que $75 \%$ dos estudantes universitários, entre 18 e 25 anos, que participaram do estudo em 2010 se consideram menos empáticos do que os estudantes de 30 anos atrás (Konrath, O'brien e Hsing, 2010). Uma outra pesquisa realizada em 2009 apontou que um em cada dez americanos apresenta traços narcisistas de personalidade que prejudicam o seu interesse pelas vidas de outras pessoas (Twenge e Campbell, 2009). E um outro estudo recente realizado na Universidade do Michigan (Chopik, O'brien e Konrath, 2016) elencou o nível empático de 63 países num questionário online que obteve 104.365 respostas. A pesquisa considerou temas como a autoestima, o bem-estar, a saúde emocional e o comportamento "pró-social" dos indivíduos. O Brasil foi classificado como o 51으 país na escala empática.

De acordo com Krznaric (2015), o desenvolvimento da empatia, embora possa ser trabalhado em qualquer momento durante a vida, deve ser estimulado desde a infância, especialmente depois dos 6 e 7 anos, período quando a criança começa a compreender as emoções alheias. Na fase do estágio operatório-concreto, dos 7 aos 11 ou 12 anos, a criança começa o declínio do egocentrismo e se torna mais socializada e capaz de entender o ponto de vista do outro. A partir deste momento a criança desenvolve a capacidade de estabelecer relações interpessoais e as interações começam a ser mais bem exploradas, sendo possível a realização de trabalhos em grupo, de modo cooperativo, sem a perda da autonomia pessoal (Piaget, 1967). Alguns cuidados, entretanto, precisam ser tomados nesta fase, como atentar ao desenvolvimento dos valores morais por meio de diálogos e histórias contra o preconceito, bullying, guerras. Assim, essa fase é um excelente momento para desenvolver a empatia e o aprimoramento das relações interpessoais através de gestos, experiências e brincadeiras (Krznaric, 2015).

Tendo em vista o público-alvo definido para o trabalho de conclusão de curso em Design Visual, a pesquisa de campo foi realizada em uma escola de Porto Alegre, o Colégio Estadual Marechal Floriano Peixoto, com uma turma do terceiro ano do ensino fundamental. A turma possui 30 alunos entre 8 e 11 anos de idade. Durante o período de imersão no contexto, foram realizadas observações em sala de aula, entrevistas com professoras e diretora e testes com os alunos participantes . Conforme quadro abaixo: 
Quadro 1: Processo de imersão no contexto

\begin{tabular}{|c|c|c|c|}
\hline $\begin{array}{l}\text { Processo de imersão } \\
\text { no contexto }\end{array}$ & Primeira visita & Segunda visita & Terceira visita \\
\hline $\begin{array}{l}\text { Observações } \\
\text { em sala de aula }\end{array}$ & $\begin{array}{l}\text { Correção de testes de } \\
\text { português e contação de } \\
\text { histórias. } \\
28 / 06 / 17 \text { - } 14 \mathrm{~h} \text { às } 16 \mathrm{~h}\end{array}$ & $\begin{array}{l}\text { Correção de testes de } \\
\text { ciências e leitura de textos } \\
\text { pelos alunos. } \\
16 / 08 / 17 \text { - } 14 \mathrm{~h} \text { às } 15 \mathrm{~h}\end{array}$ & $\begin{array}{l}\text { Correção de testes } \\
\text { de matemática. } \\
25 / 10 / 17-14 \mathrm{~h} \text { às } 15 \mathrm{~h}\end{array}$ \\
\hline Entrevistas & $\begin{array}{l}\text { Entrevista informal com a } \\
\text { diretora. Duração de } 15 \\
\text { min e registro escrito. } \\
\text { 05/07/17 - } 19 \mathrm{~h} 30 \text { às } \\
\text { 19h45 } \\
\text { Local: Colégio Marechal } \\
\text { Floriano Peixoto }\end{array}$ & $\begin{array}{l}\text { Entrevista informal com a } \\
\text { professora. Duração de } 15 \\
\text { min e registro escrito. } \\
\text { 10/07/17 - } 15 \text { h30 às } \\
\text { 15h45 } \\
\text { Local: Colégio Marechal } \\
\text { Floriano Peixoto }\end{array}$ & $\begin{array}{l}\text { Entrevista com a } \\
\text { psicopedagoga Luciana } \\
\text { Corso. Duração de } 20 \text { min } \\
\text { e registro por gravação. } \\
\text { 04/10/17 - 10h às } 10 \mathrm{~h} 20 \\
\text { Local: UFRGS }\end{array}$ \\
\hline Testes & $\begin{array}{l}\text { Teste da } 1 \text { a alternativa na } \\
\text { turma do terceiro ano. } \\
\text { Total de alunos presentes: } \\
26 . \\
07 / 11 / 17 \text { - } 14 \mathrm{~h} \text { às } 16 \mathrm{~h}\end{array}$ & $\begin{array}{l}\text { Teste da } 2 \text { a alternativa na } \\
\text { turma do terceiro ano. } \\
\text { Total de alunos presentes: } \\
25 . \\
14 / 11 / 17 \text { - } 14 \text { h às } 16 \mathrm{~h}\end{array}$ & $\begin{array}{l}\text { Teste de verificação na } \\
\text { turma do terceiro ano. } \\
\text { Total de alunos presentes: } \\
20 . \\
13 / 03 / 18-14 \mathrm{~h} \text { às } 15 \mathrm{~h}\end{array}$ \\
\hline
\end{tabular}

Fonte: autora (2017)

Nas primeiras visitas à escola foram realizadas observações na sala de aula, onde foi observado uma grande diversidade, social e comportamental nos alunos. Alguns são muito interessados e gostam de responder às perguntas da professora, porém outros demonstram desinteresse e falta de atenção. Além disso, foi constatada uma diferença de condição social, pela observação dos materiais escolares de cada aluno. Também foi possível acompanhar algumas atividades de classe, como correções de português, de ciências, leituras de contos infantis e "idas" ao banheiro.

Nas entrevistas realizadas com a diretora e com a professora da turma, ambas com duração de 15 minutos e registradas por escrito, alguns pontos ficaram evidentes. A principal queixa de ambas é com relação à falta de apoio familiar, pois muitas famílias não acompanham o rendimento escolar dos alunos e só aparecem na escola quando a diretora ameaça chamar o conselho tutelar. A diretora ainda demonstra preocupação com o aumento de casos de adolescentes, entre 12 e 15 anos, com quadros de depressão e síndrome do pânico. Com relação à turma do terceiro ano do fundamental, a professora relatou que não há casos de agressão física recorrentes, sendo o mais comum ataques de caráter psicológico, como fofocas, apelidos "maldosos" e implicância entre colegas. Ela conta que já tentou aproximar os alunos por meio de algumas atividades diferenciadas, como o "corredor do abraço", onde eles deveriam se abraçar, e "mensagens carinhosas" que eles deveriam escrever para cada um dos colegas. Entretanto, segundo a professora, nenhuma das atividades obteve resultados positivos. 
Uma terceira entrevista foi realizada com Luciana Corso, professora pelo Departamento de Estudos Especializados na área de Psicopedagogia da Universidade Federal do Rio Grande do Sul (UFRGS) há 20 anos. Ela aponta que os fatores emocionais e interpessoais são pouco estimulados dentro da escola e que estes são importantes para o desenvolvimento completo da criança. Existe uma tendência a crer que todas as crianças amadurecem, emocionalmente de maneira igual e no mesmo ritmo, porém isso não é verdade. Conforme Corso, o mais importante, no contexto escolar e na vida, é desenvolver o respeito, e, desta forma, estimular as habilidades socioemocionais pode ajudar, pois quando o indivíduo se identifica com o outro, consegue entender o que o outro está sentindo e se imaginar no lugar deste. Assim, o indivíduo terá maior condição de refletir antes de tomar uma atitude que poderá prejudicar alguém.

As observações e entrevistas realizadas demonstram que os alunos apresentam um nível baixo de empatia, uma vez que foram identificadas atitudes de natureza agressiva nas relações interpessoais.

Para confirmar esse fato foi aplicado um teste de empatia, a Escala de Empatia para Crianças e Adolescentes (EECA), na turma investigada. A EECA é uma medida com 22 itens que devem ser respondidos com "sim" ou "não", desenvolvida por Brenda Bryant (1982) da University of California. Bryant (1982) construiu a Escala de Empatia para Crianças e Adolescentes a partir da definição de que empatia é "uma resposta emocional vicária às experiências emocionais dos outros, percebidas pelo sujeito" (1982, p.414). O questionário foi adaptado pela autora com 20 frases e foi respondido por 26 alunos da turma investigada. Para essa abordagem foram escolhidas frases como: "Ver um menino que está chorando me faz sentir vontade de chorar" e "Crianças que não tem amigos, provavelmente não querem ter". Os resultados obtidos apresentam-se no quadro a seguir:

Quadro 2: Média geral do teste de empatia realizado na turma

\begin{tabular}{llll} 
Alunos & Média $(0 \%-100 \%)$ & Nota mínima $(0-20)$ & Nota máxima (0-20) \\
\hline Total & $52,7 \%$ & 4 & 17 \\
\hline Meninos (12) & $53,3 \%$ & 4 & 16 \\
\hline Meninas (13) & $52,7 \%$ & 6 & 17
\end{tabular}

Fonte: autora (2017)

Em termos gerais, a empatia pode ser mais desenvolvida nos participantes, uma vez que metade da turma apresenta características empáticas em um nível acima da média e metade apresenta características empáticas num nível muito baixo. Na perspectiva de gêneros, o nível empático entre meninos e meninas se encontra em equilíbrio, quase na mesma proporção.

A partir dos resultados obtidos na imersão, conclui-se que é necessário desenvolver e estimular as capacidades socioemocionais no ambiente escolar. Tendo em vista o público investigado, turma de terceiro ano do ensino fundamental, uma solução adequada para o problema é o desenvolvimento de um material didático socioemocional. Para referenciar a 
definição de material didático recorre-se ao conceito de Design Instrucional. De acordo com Filatro (2007) o design instrucional compreende a ação intencional e sistêmica de ensino que envolve planejar, desenvolver e aplicar métodos, técnicas, materiais e produtos educacionais em situações didáticas específicas com o objetivo de promover a aprendizagem humana. O Design Instrucional consiste no conjunto de atividades que determinam um problema de aprendizagem e a sua solução adequada por meio de um projeto e sua implementação (Bandeira, 2009).

Considerando que este material busca introduzir e desenvolver as capacidades socioemocionais em um ambiente escolar, as pesquisa de Ekman (2003) e Krznaric (2015) sobre as emoções e a empatia fundamentam a busca da solução mais adequada. Para Krznaric (2015), a melhor forma de desenvolver a empatia é pela experiência física, como em um teatro no qual os atores precisam personificar um personagem da maneira mais real possível e onde há uma troca tangível. Sendo assim, o material impresso foi definido como o recurso mais adequado, já que oferece uma experiência palpável. Além da experiência, Krznaric também defende que fazer uso da arte como forma de estimular a imaginação pode ajudar a desenvolver a empatia. Desse modo, inicialmente este projeto visava desenvolver uma experiência em sala de aula, na qual os alunos deveriam modificar uma história infantil já conhecida, encenando uma parte da história modificada e, por fim, montando um novo livro infantil, no qual os alunos seriam os protagonistas. Entretanto, ao testar esta proposta junto a turma participante, constatou-se que não era a melhor opção (ver quadro 2). A proposta, ainda que interessante e relacionada ao tema da empatia, oferecia muitos desafios em sala de aula e não seria uma atividade fácil de ministrar numa turma tão numerosa (26 alunos). Devido à inovação da proposta cada aluno demandaria um nível de atenção por parte do orientador que ficou inviável de cumprir.

Após esse teste, uma nova alternativa foi concebida, e consistia num material didático socioemocional focado nas cinco emoções básicas de Ekman (2003): alegria, raiva, nojo, tristeza e medo. O conceito das cinco emoções básicas é apresentado aos alunos por meio de uma história infantil, e depois são propostas atividades para os alunos visando o aprendizado socioemocional. 0 1 ㅇ exercício visa estimular os participantes a representar visualmente cada uma das 5 emoções por meio de expressões faciais. O 2o exercício busca trabalhar os "gatilhos emocionais" que despertam cada uma das cinco emoções nos alunos, com uso de cartas que questionam o que provocam suas emoções. Foi projetado um dado em que cada face apresenta 1 das 5 emoções a fim do aluno compartilhar com os colegas. $\mathrm{O} 3$ 을 exercício consiste em um tabuleiro que apresenta a jornada das emoções de um personagem infantil. A professora deve selecionar 5 situações de um conto infantil que esteja sendo trabalhado em sala de aula. O aluno deverá definir qual das 5 emoções o personagem experienciou e colocar uma peça com o nome da emoção no local indicado no tabuleiro. A alternativa foi testada em sala de aula na turma investigada. Os alunos acompanharam a proposta com atenção e interesse e foi possível ajudá-los a realizarem as atividades sem maiores dificuldades. A professora e os alunos elogiaram as atividades. Um teste de verificação foi realizado com uma nova turma do terceiro ano (checar quadro 1) utilizando o protótipo final. Os 20 participantes demonstraram facilidade em compreender as atividades e muito interesse em realizá-las. $O$ exercício de representar as expressões faciais de cada uma das 5 emoções foi muito bem aceito, os alunos relutaram em encerrar a atividade. As expressões nem sempre ficavam exatas, mas os resultados eram muito próximos da emoção trabalhada. Os alunos demonstraram independência ao realizar as atividades e alguns se voluntariaram para ajudar os colegas. 
Figura 1: Registro do teste da 2 a alternativa na turma do terceiro ano (ver quadro 1 ).

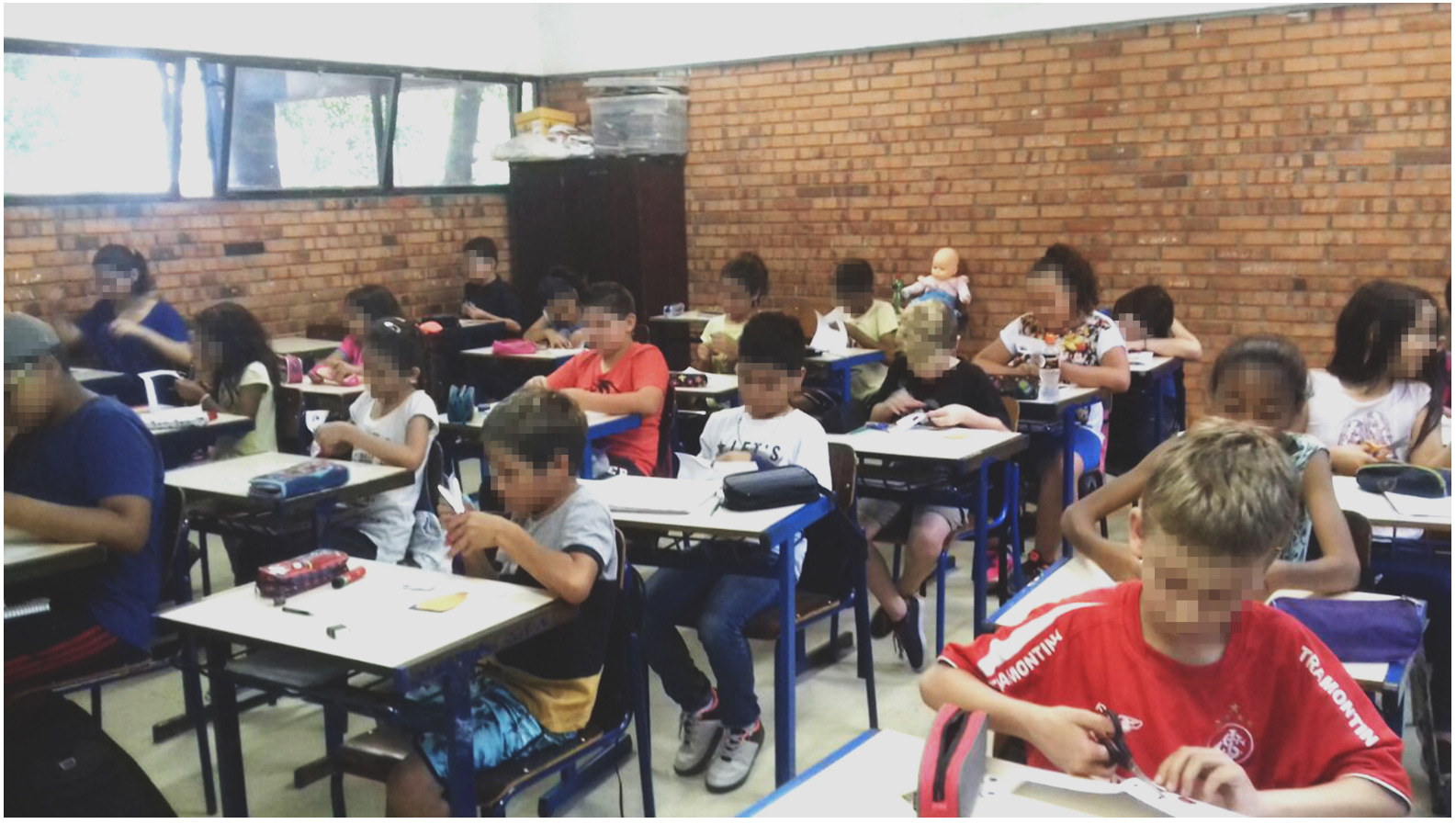

Fonte: Autora (2017)

\section{Metodologia}

A metodologia selecionada para a realização deste projeto de design visual foi a metodologia associada ao design thinking e ao design centrado no ser humano, desenvolvida pela IDEO (BROWN, 2009).

Design thinking se distancia das abordagens tradicionais, uma vez que o seu processo é muito mais humano e usa habilidades que são ignoradas por outras metodologias. Conta com a capacidade intuitiva e com o reconhecimento de padrões para construir ideias que possuem significados emocionais e funcionais. Afinal, se basear puramente nas emoções e na intuição não funciona, mas se basear puramente no lado racional e analítico também não. O Design Thinking oferece uma terceira possibilidade, uma vez que integra estes dois lados (BROWN \& WYATT, 2010).

O processo de design thinking consiste em uma sobreposição de espaços ao invés de uma sequência de ações, pois assim é possível retornar à qualquer área em qualquer momento durante o processo. Estes espaços são separados em três grandes áreas: inspiração (ouvir), ideação (criar) e implementação (implementar). Ouvir se relaciona com a etapa na qual é necessário entender o problema e o público para assim encontrar as melhores soluções, Criar é a etapa onde acontece a geração de ideias e seus testes iniciais, e a etapa Implementar é quando o projeto começa a fazer parte da vida dos usuários (BROWN \& WYATT, 2010).

Neste projeto o processo foi dividido em cinco etapas. Na primeira etapa, de Imersão, o importante é entender o contexto em que o usuário está inserido, quais são suas necessidades e coletar o máximo de informações que possam ajudar a encontrar a solução ideal. A etapa dois consiste em selecionar os materiais coletadas e realizar uma análise e síntese das informações 
mais relevantes. A etapa três é o momento de geração de ideias, a partir de tudo que foi coletado e analisado deve-se gerar o máximo de alternativas possíveis, após o brainstorming, as alternativas deverão ser analisadas, de preferência testadas, e uma destas deverá ser selecionada como conceito final. A etapa quatro consiste na etapa de prototipação, onde a identidade visual deverá ser desenvolvida, bem como todos os demais materiais. A etapa cinco, é a etapa final onde o protótipo deverá ser validado, melhorias poderão ser identificadas e parceiros poderão ser contatados (VIANNA et. al., 2012).

Figura 2: Etapas do Design Thinking

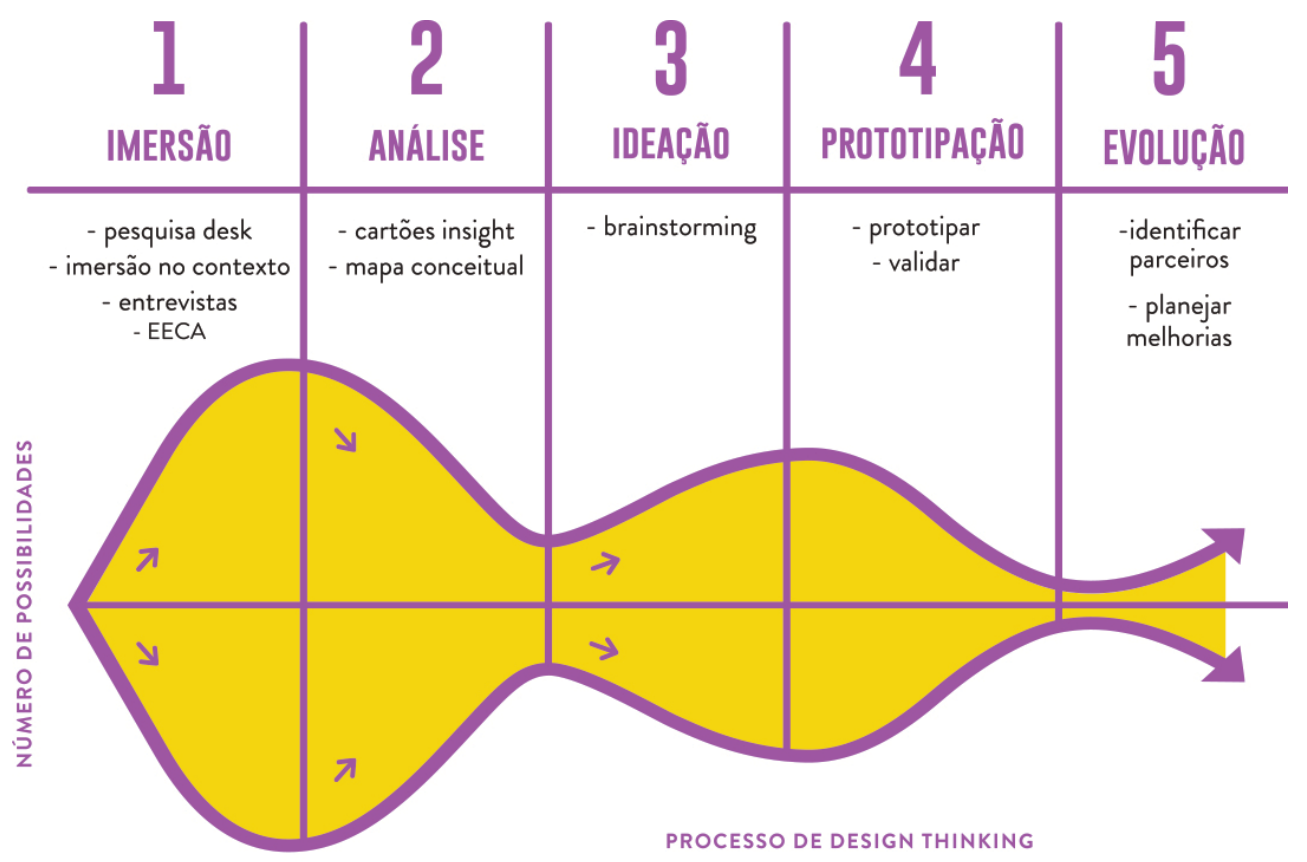

Fonte: Vianna et. al., 2012 e IDEO, 2017. Adaptado pela autora.

\section{Design como fator de inovação no contexto escolar}

A inovação no contexto do design pode ser entendida como a busca por alternativas que ainda não haviam sido pensadas e que oferecem qualidades transformadoras. Já a inovação no contexto escolar, por ser um ambiente social, pode ser considerada uma inovação social, que é o desenvolvimento de novas ideias, serviços, produtos e modelos que apresentam uma melhor solução para diferentes problemas sociais (European Comission, 2013).

\subsection{Material didático socioemocional: um projeto guiado pela experiência, storytelling e as 5 emoções básicas}

O projeto buscou desenvolver um material didático socioemocional com foco em três diretrizes: experiência, para que o aprendizado seja tangível, o storytelling, que ajuda a contar uma história e a conectar pontos que geram uma experiência marcante, que por sua vez, gera um aprendizado; e as cinco emoções básicas, pois saber reconhecer as próprias emoções e as situações que desencadeiam certos sentimentos, ajuda a alcançar uma maior inteligência emocional e ajuda a entender melhor as emoções dos outros, o que aumenta a habilidade empática e melhora as relações interpessoais. A utilização das expressões faciais das cinco 
emoções básicas como o centro do projeto buscou um resultado inovador, interativo e visualmente atrativo.

As diretrizes trabalhadas na identidade visual e nas demais peças gráficas incluíram: linguagem infantil e divertida, do ponto de vista do projeto gráfico a identidade precisava conversar de maneira afetiva com o público-alvo; forte e diversificada, além disso precisava ser marcante, bem construída, e apresentar possibilidades de variações.

Do ponto de vista estrutural o material didático foi construído de maneira física, contendo um livro infantil, um manual do docente, 3 atividades didáticas e embalagens. Além disso, o projeto desenvolveu também um website, onde todas as peças presentes nesse material didático podem ser baixadas por download (visando maior acesso).

O nome "as cinco emoções" foi a opção escolhida para a marca, pois foi o termo que melhor representou a essência desse material didático. A partir da definição do nome "as cinco emoções" se iniciou a geração de alternativas gráficas para a marca. A alternativa selecionada apresenta o próprio nome do produto como o logotipo principal. A palavra "cinco" possui maior peso, formas marcantes e arredondadas, e as cinco cores presentes dentro de cada uma das letras da palavra "cinco" referenciam cada uma das cinco emoções. O conceito associado à cada uma das cores foi: azul simboliza tristeza por ser associada a água e ao frio, a cor roxa simboliza medo por ser associada ao mistério, a cor verde simboliza nojo por ser associada ao enjôo e ao brócolis, a cor vermelha simboliza raiva por ser associada ao fogo e ao perigo, a cor amarela simboliza alegria por ser associada ao sol, ao brilho e ao otimismo.

A tipografia da palavra "cinco" foi inspirada na fonte Gothiks da Blackletra. Entretanto, a Gothiks possui traços mais duros e retos, enquanto que a tipografia adaptada possui traços arredondados que transmitem uma maior leveza. Já a fonte secundária que está presente nas palavras "as" e "emoções" é a Brandon Grotesque. Ela é uma fonte sem serifa geométrica inspirada nas fontes dos anos 1920 e 1930 e oferece uma boa legibilidade, assim como transmite um certo carisma devido ao seu acabamento mais arredondado.

Figura 3: Identidade Visual "As Cindo Emoções"

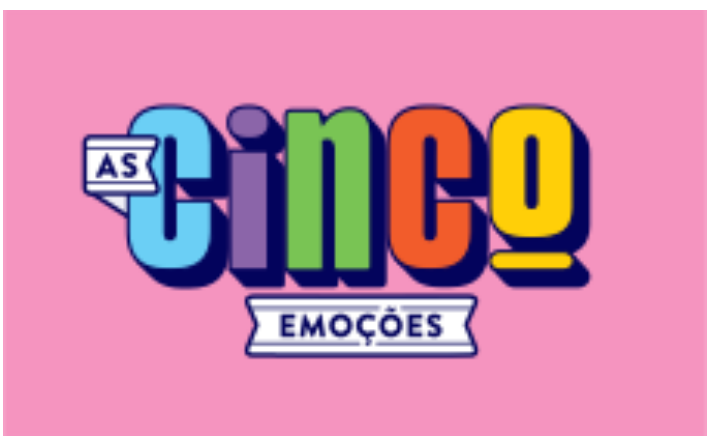

Fonte: Autora (2017)

O livro infantil, que possui formato $18 \times 18 \mathrm{~cm}$ e um total de 16 páginas, apresenta no gráfico ilustrações que contam a história da menina Luisa de acordo com as 5 emoções vivenciadas por ela. Um requisito que surgiu durante o processo de desenvolvimento do livro foi o de não usar ilustrações que apresentassem as expressões faciais de cada uma das cinco emoções, pois, a atividade 


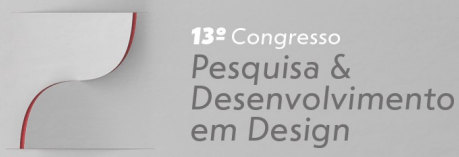

subsequente é a de construir as expressões faciais. Sendo assim, foi necessário desenvolver uma linguagem ilustrativa que representasse as emoções sem fazer uso das expressões em si. $O$ resultado foi uma composição focada no cenário no qual Luisa está inserida, a casa de praia. As cores e a tipografia foram utilizadas para ajudar a transmitir as emoções de maneira visual.

Figura 4: Algumas páginas do "Livro das emoções
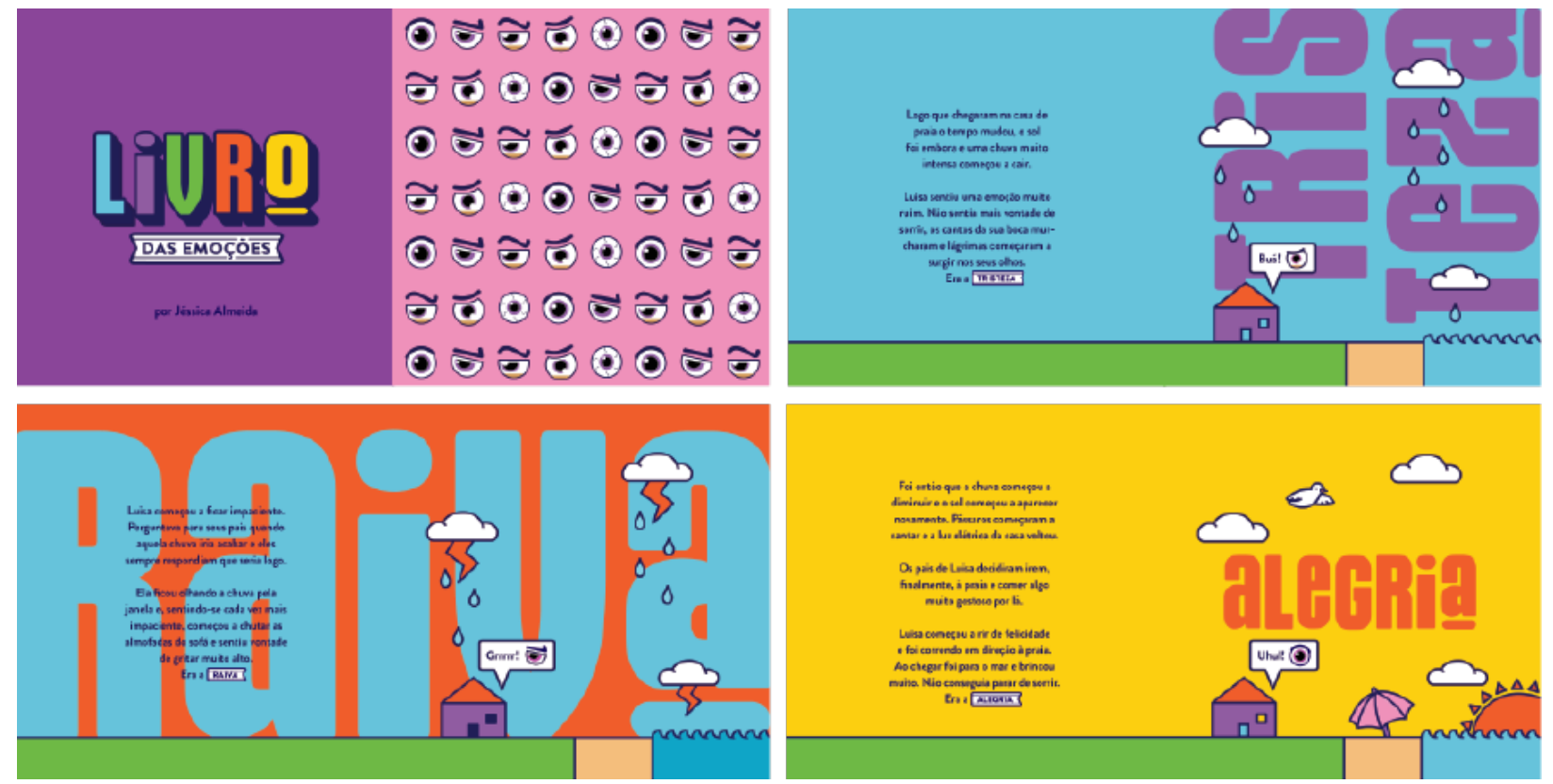

Fonte: Autora (2017)

O exercício "As cinco emoções" consiste em um material didático que busca desenvolver a compreensão sobre os cinco tipos de emoções básicas de maneira visual e interativa, sendo este a principal atividade. Cada aluno pode construir as suas emoções básicas: alegria, medo, raiva, tristeza e nojo, usando os tons de pele, cor de olhos e boca que mais se identificarem. O aluno, ao representar visualmente cada uma das expressões faciais, estará realizando um processo de auto-avaliação das próprias emoções e da própria identidade. Com o objetivo de estimular a empatia cognitiva, uma outra atividade proposta é a de representar graficamente as emoções dos colegas. Outro exercício é o "Dado das emoções", que consiste em uma atividade que busca desenvolver a empatia emocional através do reconhecimento das diferentes situações em que o aluno sente cada uma das 5 emoções em relação às situações que os colegas sentem. Identificando o que desperta determinadas emoções em si próprios, e os gatilhos emocionais dos colegas, eles conseguem se identificar uns nos outros. O último material didático é "A Jornada das Emoções", uma atividade que propõe que o aluno realize um processo empático ao se imaginar no lugar de um personagem de uma história infantil. Por fim, foi desenvolvido um manual do docente, onde se encontra um passo-a-passo sobre como utilizar estes materiais didáticos em sala de aula. 
Figura 5: Diferentes combinações de expressões faciais do exercício 1: "As cinco emoções"

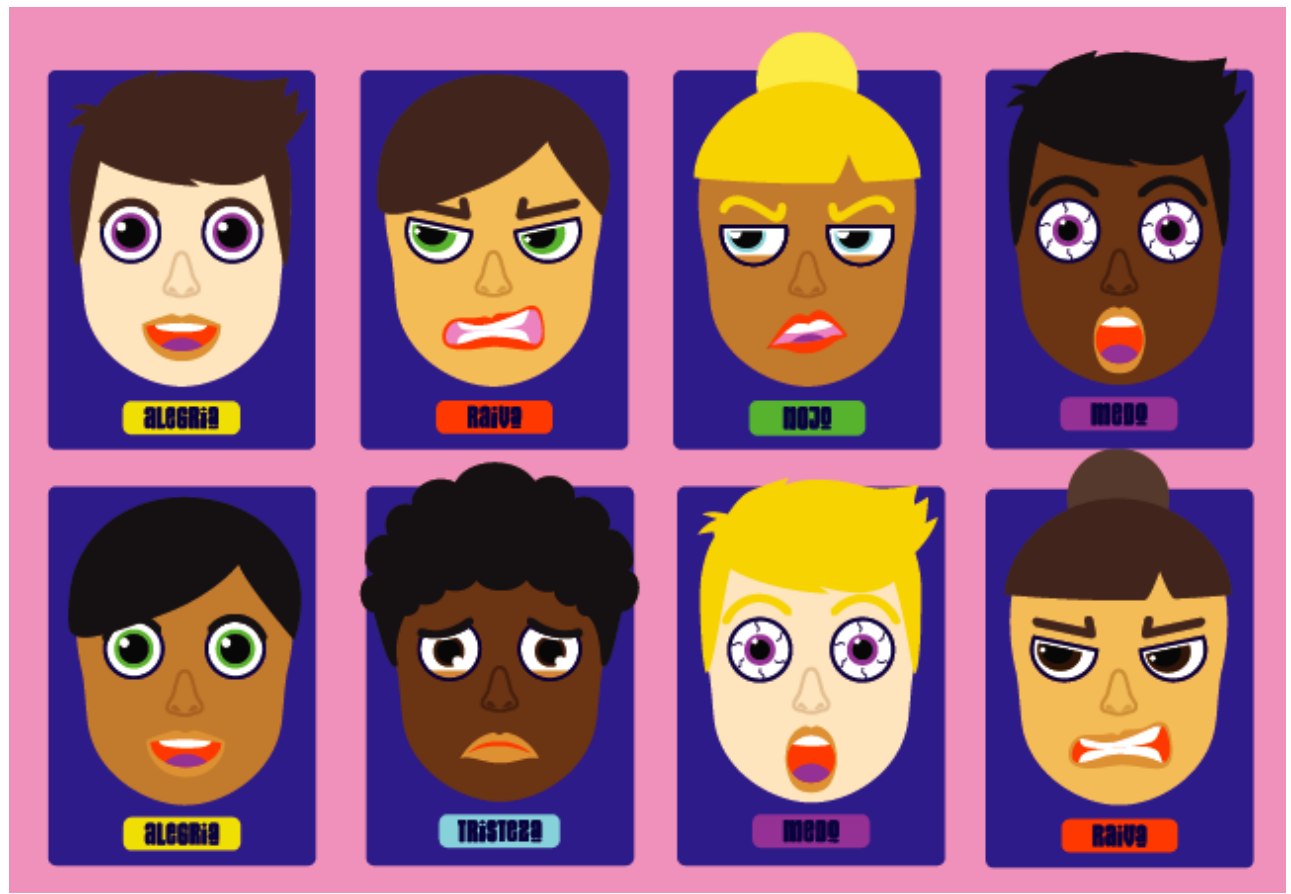

Fonte: Autora (2017)

Figura 6: Exercício 2 - "Dado das emoções" -- e exercício 3 - "Jornada das emoções"

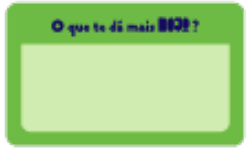

Oquato to mos atutia?

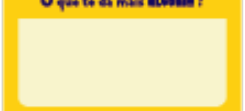

Oque to di mais numben ?
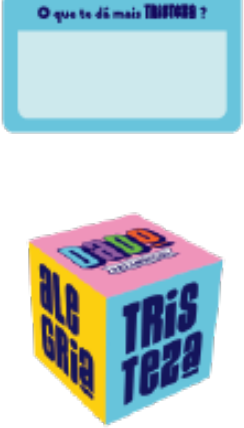

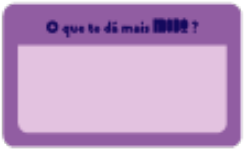

Oque to \& mois baile?

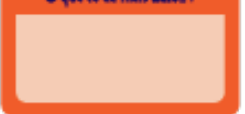

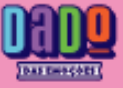

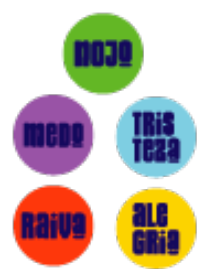

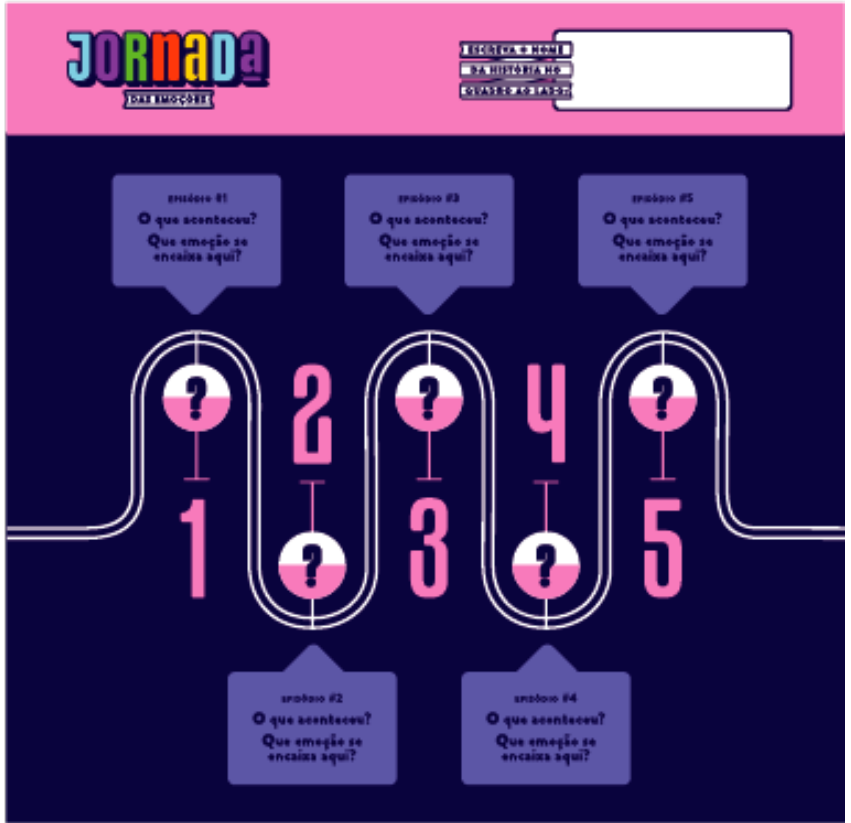

Fonte: Autora (2017) 
Figura 7: Algumas páginas do "Manual do Docente"
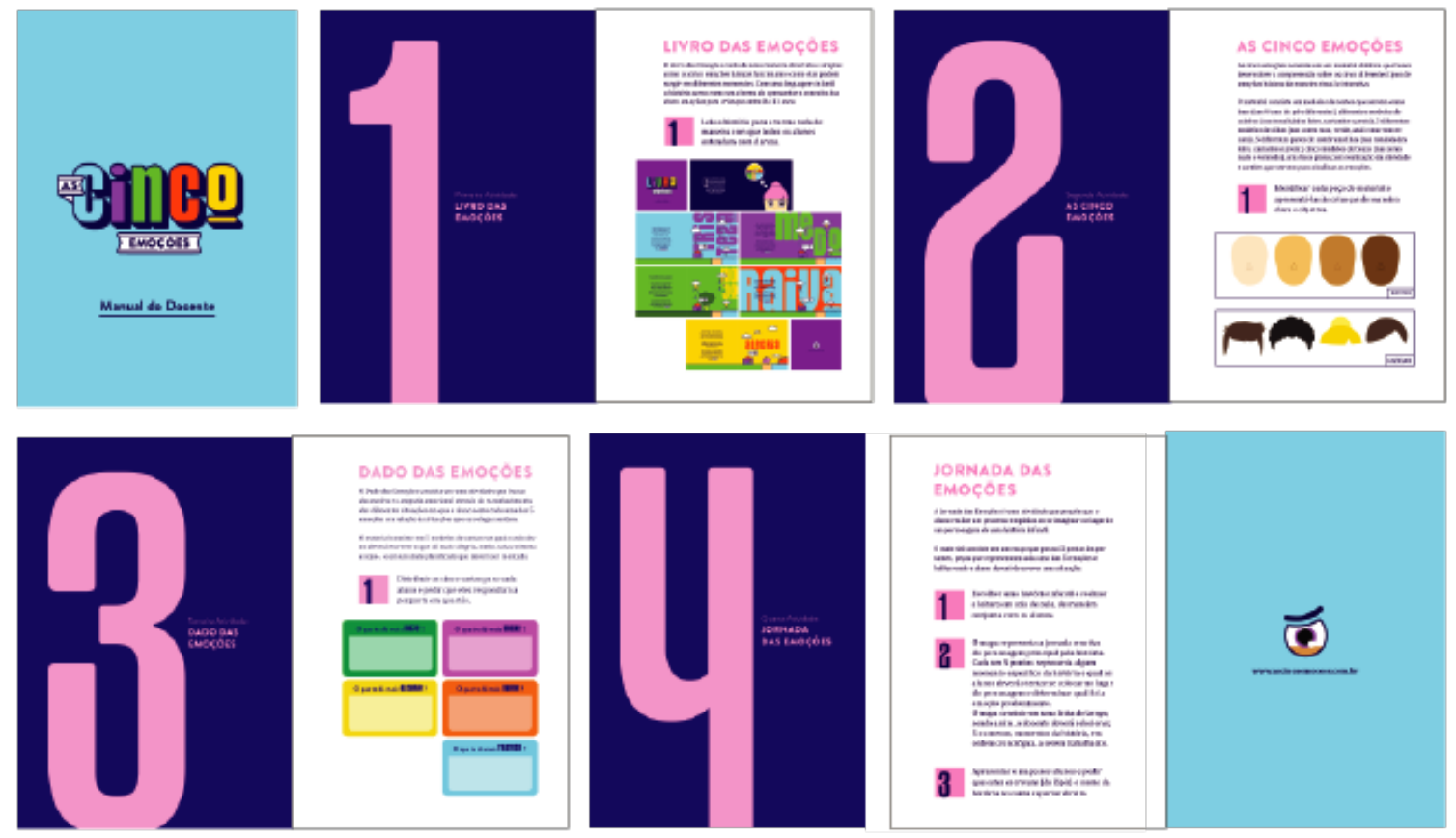

Fonte: Autora (2017)

\section{Conclusão}

Considerando que as habilidades cognitivas ainda são mais priorizadas no ambiente escolar, a proposta do projeto desenvolvido neste trabalho de conclusão de curso em Design visual é de introduzir uma ferramenta que pode oportunizar a valorização e o aprendizado das habilidades socioemocionais no contexto escolar, com o objetivo de causar um impacto positivo nas relações interpessoais dos alunos. Ressaltando que para desenvolver de maneira efetiva as habilidades socioemocionais dos alunos é necessário um trabalho a longo prazo, por parte da escola e professores.

Cabe destacar que nesta pesquisa a inovação se encontra no próprio problema, uma vez que existem poucos materiais didáticos orientados ao aprendizado socioemocional disponíveis no mercado, assim como o exercício didático das capacidades socioemocionais é pouco praticado nas escolas, ou em muitos casos nem o é. As diretrizes projetais do material didático socioemocional pautaram-se para a atratividade e motivação dos usuários. O material didático desenvolvido teve como foco as relações pessoais e interpessoais dos alunos, podendo ser considerado um material didático socioemocional interativo.

\section{Referências}

BANDEIRA, Denise. Materiais Didáticos. Curitiba, PR: IESDE, 2009.

BROWN, T; Change by Design: how design thinking transforms organizations and inspires innovation. Estados Unidos: Harper Business. 2009. 
BROWN, T; WYATT, J. Design Thinking for Social Innovation. Stanford Social Innovation Review, [S.I.], v. 8, n. 1, winter 2010. Disponível em: < https://ssir.org/articles/entry/ design_thinking_for_social_innovation>. Acesso em: 14 abr. 2017.

BRYANT, B. K. (1982). An index of empathy for children and adolescents. Child Development. Abr., 1982, Vol. 53, No. 2, pp. 413-425.

CHOPIK, William; O'BRIEN, Ed; KONRATH, Sara. Differences in Empathic Concern and Perspective Taking Across 63 Countries. Estados Unidos: Journal of Cross-Cultural Psychology, 2016.

EKMAN, Paul. Emotions Revealed: recognizing faces and feelings to improve communication and emotional life. Estados Unidos: Times Books, 2003.

EUROPEAN COMISSION. Guide to social innovation. 2013. Disponível em: <http:// s3platform.jrc.ec.europa.eu/documents/20182/84453_Guide_to_Social_Innovation.pdf>. Acesso em: 20 abr. 2017.

FILATRO, Andréa. Design Instrucional Contextualizado: educação e tecnologia. São Paulo: SENAC, 2007.

FREITAS, Olga. Equipamentos e materiais didáticos. Brasilia: Universidade de Brasilia, 2007.

IDEO. The Field Guide to Human-Centered Design. 2015. Disponível em: <http:// www.designkit.org/resources/1>. Acesso em: 10 mai. 2017.

INSTITUTO ALANA. A importância da empatia na educação. Ed. 1. São Paulo, 2016. KONRATH, Sara; O'BRIEN, Edward; HSING, Courtney. Changes in Dispositional Empathy in American College Students Over Time: A Meta-Analysis. Estados unidos: Universidade do Michigan, 2010.

KRZNARIC, Roman. O Poder da Empatia: a arte de se colocar no lugar do outro para transformar o mundo. 1 ed. Rio de Janeiro: Zahar, 2015.

PIAGET, Jean. Seis estudos de psicologia. Rio de Janeiro: Forense Editora, 1967.

TWENGE, J. M; CAMPBELL, W. K. The Narcissism Epidemic: Living in the Age of Entitlement. Free Press, 2009.

VIANNA, M. et al. Design Thinking: inovação em negócios. Rio de Janeiro: MJV Press, 2012. Disponível em: <https://cdn2.hubspot.net/hubfs/455690/Ofertas/E-books/Arquivos/ Livro_Design_Thinking_-_Inovao_Negcios.pdf>. Acesso em: 10 mai. 2017. 